\title{
SISTEMA DE SIMULAÇÃO DE PRESENÇA RESIDENCIAL
}

\author{
Thiago Dantas da Silva \\ Bolsista do PIBITI - CNPq - IFRN \\ thiagogo_sk8@hotmail.com. \\ Antonio Luiz Pereira de Siqueira Campos \\ Doutor em Engenharia Elétrica. Professor da UFRN. \\ antonioluiz@ufrnet.br. \\ Francisco Sales de Lima Filho \\ Professor de Redes de Computadores do IFRN. Mestrando em Engenharia Elétrica. \\ salesfilho@cefetrn.br.
}

\section{RESUMO}

Neste artigo é detalhado um sistema eletrônico de baixo custo para ser empregado em automação residencial, visando a simulação de presença residencial. Para isso, foram empregadas técnicas de comunicação com portadora em linhas de potência (Power Line Carrier Communications - PLCC), que oferecem métodos de instalação de redes domésticas de automação economicamente viáveis, em qualquer residência. Este projeto deu continuidade a diversas pesquisas desenvolvidas pelo Prof. Antonio Campos, que seguem a mesma linha dessa proposta. O sistema é um dispositivo de acionamento de cargas remoto controlado por um programa computacional, que faz a interface homemmáquina com o usuário.

PALAVRAS-CHAVE: Domótica, Simulação de presença residencial, Técnicas PLC, Automação residencial, Controle liga/desliga, Baixo custo.

\section{HOME PRESENCE SIMULATION SYSTEM}

\begin{abstract}
In this paper is detailed a comprehensive electronic system for low cost to be used in home automation, in order to simulate residential presence. For this, techniques of Power Line Carrier Communications (PLCC) were used, which provide methods of installing home networking automation economically viable in any residence. This project continued to several surveys conducted by Prof. Antonio Campos, who are in line with this proposal. The system is a device to drive loads remote controlled by a computer program that makes the man-machine interface with the User.
\end{abstract}

KEY-WORDS: Domotics, Home Presence Residential System, PLC Techniques, Home automation, ON/OFF Control, Low Cost. 


\section{SISTEMA DE SIMULAÇÃO DE PRESENÇA RESIDENCIAL}

\section{INTRODUÇÃO}

Existe uma série de trabalhos que abordam o tema automação residencial. Os avanços tecnológicos e a busca por conforto e segurança vêm fazendo com que a cada dia as residências tenham mais e melhores sistemas automatizados. A principal ênfase destes sistemas está no gerenciamento de recursos, segurança, conforto e, atualmente, em entretenimento.

Muitos dos trabalhos publicados apresentam sistemas que detectam eventos, como a presença dos habitantes e suas ações, ou possuem sensores que conseguem capturar mudanças nas condições do ambiente. A estes eventos são aplicadas reações que estão previamente configuradas.

Atualmente, um dos grandes problemas da sociedade moderna está relacionado com a falta de segurança pessoal e de bens. Tendo em vista o aumento da criminalidade e delinquiência nos últimos anos, as implementações de sistemas voltados para o monitoramento e segurança estão cada vez mais comuns. Além disso, os gastos com segurança neste período têm somado valores expressivos, na contratação de serviços especializados de vigilância e monitoramento.

Baseado nisso, o objetivo principal deste projeto foi desenvolver um sistema eletrônico de baixo custo que pudesse ser empregado em automação residencial, visando à simulação de presença residencial. Para isso, foram empregadas técnicas de comunicação com portadora em linhas de potência (Power Line Carrier Communications - PLCC). Estas técnicas oferecem métodos de instalação de redes domésticas de automação economicamente viáveis, em qualquer residência. Este projeto deu continuidade a diversas pesquisas desenvolvidas pelo Prof. Dr. Antonio Campos (CAMPOS, 2006), (CAMPOS, 2007). Neste artigo, serão abordados os detalhes da pesquisa e a descrição do sistema implementado.

\section{FUNDAMENTAÇÃO TEÓRICA}

O termo Domótica é usado para designar residências que empregam serviços automatizados. Tecnicamente falando, uma rede domótica pode ser representada por um conjunto de serviços interligados que realizam diversas funções de gerenciamento e atuação, podendo estar conectados entre si por meio de uma rede de comunicação interna e/ou externa.

Neste contexto, aparece a tecnologia Power Line Carrier (PLC), que possibilita a automação residencial sem a necessidade de uma rede dedicada para tanto. Esta tecnologia utiliza a rede elétrica para transmissão de sinais, em uma comunicação ponto-a-ponto dentro de um prédio ou de um prédio a outro (MAINARDI, 2005).

Entretanto, a rede elétrica, inicialmente, não foi desenvolvida para ser utilizada como um canal de comunicação, pois contém ruídos que tornam quase impraticável a transmissão de dados. Após várias pesquisas e testes, foram desenvolvidas técnicas capazes de superar estes obstáculos tornando viável o uso da mesma para este propósito (MAINARDI, 2005). Nos Estados Unidos e na Europa, durante a década de 80, algumas empresas elaboraram e analisaram estudos sobre a rede elétrica como um canal de comunicação utilizando faixas 
de freqüências bem maiores que na década de 50 (ABRAHAM, 1992). A atenuação e o ruído foram os fatores mais estudados por estas empresas. Só a partir de 1990, utilizando níveis de potência mais baixos e freqüências mais altas é que foi possível conseguir comunicação bidirecional utilizando a rede elétrica. Em novembro de 2001 a Companhia Energética de Minas Gerais - CEMIG estava testando um projeto piloto que permitisse o acesso à Internet em banda larga, com um canal de $2 \mathrm{Mbps}$ compartilhado, através da rede elétrica. Já no ano de 2002, nos Estados Unidos, o presidente da Comissão Federal de Comunicação - FCC aprovou a tecnologia que fornece conexão em alta velocidade à Internet pela rede elétrica.

Comunicações com portadora em linhas de potência (Power line carrier Communications - PLCC) fazem parte de uma área de pesquisa que tem sido estudada há muitos anos (ABRAHAM, 1992), (MAINARDI, 2005), (CAMPOS, 2006). Sistemas comerciais têm sido difíceis de serem implementados, mas encontram muitas aplicações. Pesquisas mais recentes têm focado a solução de muitos problemas de comunicações PLC usando as últimas tecnologias de comunicações, com novos dispositivos de alta velocidade (CAMPOS, 2007).

$\mathrm{Na}$ área de automação residencial, comunicações em linhas de potência podem fornecer um meio de comunicação para interligar vários dispositivos, tais como sensores de um sistema de alarmes. Diversos estudos têm focado o emprego de redes domésticas de computadores interligadas pela rede elétrica (CAMPOS, 2007).

Técnicas PLCC são bastante conhecidas e bastante usadas em aplicações domésticas. Estima-se que quatro milhões de casas nos Estados Unidos empregam métodos de comunicação PLC. Há um grande número de sistemas comercialmente disponíveis para propósitos de automação residencial. Entretanto, esses produtos, normalmente, não são interligáveis, ou usam protocolos próprios, tornando-se pouco flexíveis.

A rede elétrica de baixa tensão $(220 \mathrm{~V})$ penetra em cada prédio industrial, comercial e residencial. Desta forma, a implementação de sistemas de comunicações, através da rede elétrica fornece consideráveis vantagens para os usuários. A rede elétrica tem a vantagem de ser uma rede de comunicação independente, já possui infraestrutura de cabeamento e pode ser usada para duplo propósito. A cobertura geográfica da rede de baixa tensão é, normalmente, larga e o acesso a ela é simples.

Muitas são as dificuldades enfrentadas em PLCC. A rede elétrica não é usada com propósitos de comunicações e as principais dificuldades enfrentadas, como fortes interferências, atenuação e impedância variável, têm limitado os dispositivos PLC para uso de automação residencial. Entretanto, com o uso criterioso de modernas técnicas de comunicações, tais como técnicas de espalhamento espectral, podem-se ultrapassar essas dificuldades.

\section{JUSTIFICATIVA}

Aliada à necessidade de sistemas que propiciem maior conforto e segurança aos seus usuários, tem-se a automação residencial, que segue em crescente desenvolvimento e vem conquistando o mercado nos segmentos de controle de iluminação, automação de tarefas domésticas, controle de ar condicionado, sistema de segurança e monitoramento, controles 
de acesso, entre outros. Trata-se de um conjunto de novas tecnologias que apresentam diversos benefícios a fim de oferecer bem-estar e comodidade, atendendo às necessidades de maneira econômica e eficiente.

Além disso, a necessidade de equipamentos que auxiliem e tornem mais fácil as ações de monitoramento e acionamento de sistemas de segurança tem impulsionado uma procura crescente de novas soluções e tecnologias. Estas devem responder aos desafios existentes no controle de acesso a ambientes e, simultaneamente, devem ser tecnicamente eficientes, de fácil utilização e baixo custo.

Por outro lado, o controle de equipamentos eletro-eletrônicos, em horários préprogramados, pode ser utilizado como uma ferramenta para aumentar a segurança de um ambiente. Um dispositivo com tal controle teria função de simular a presença de pessoas neste ambiente em caso de viagens ou ausência prolongada, inibindo dessa forma atos de vandalismo ou furtos.

Um sistema de simulação de presença residencial também pode ser usado para irrigação automática de jardins, persianas podem ser abertas em horários estabelecidos, luzes podem ser ligadas em ordem e horários estabelecidos pelo usuário.

\section{DESCRIÇÃO DOS SISTEMAS}

O sistema implementado foi projetado para acionamento remoto de lâmpadas do tipo liga/desliga. O sistema é composto por 01 (um) transmissor e por, no máximo, 09 (nove) receptores. O sistema transmissor fica conectado a um computador pessoal (Personal Computer - PC) que controla o acionamento das lâmpadas. A Figura 1 ilustra o diagrama de blocos do transmissor. Como serão acionados até 09 (nove) lâmpadas, serão necessários apenas 4 (quatro) bits de dados (D0 - D3), pois isso permite o acionamento de até 15 (quinze) lâmpadas, excetuando-se a palavra 0000, que gera a onda fundamental.

O conversor D/A (DAC) é o TLC 7226, muito usado em controle de processos, teste automático de equipamentos, calibração automática de sistemas, dentre outras aplicações. Ele é um DAC de 8 bits, dos quais são utilizados apenas os quatro bits menos significativos e aterrados os outros quatro bits mais significativos. A interface paralela utiliza o já conhecido sistema com transistores BC547.

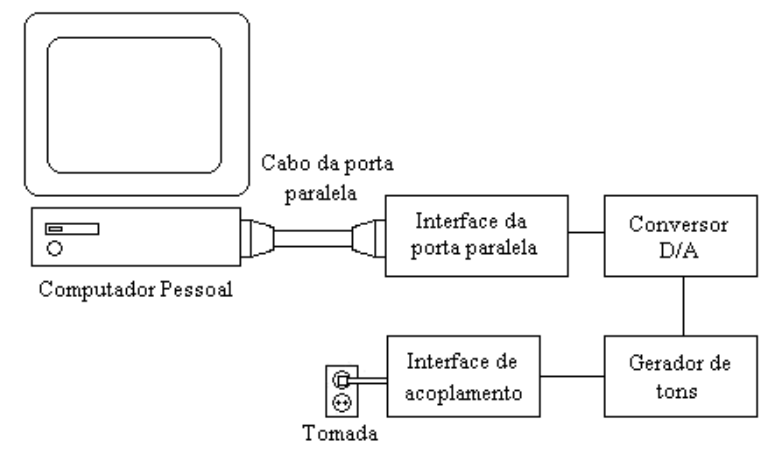

Figura 1 - Diagrama de blocos do sistema transmissor. 


\section{INTERFACE DE ACOPLAMENTO}

Um dos circuitos mais importantes do sistema é a interface de acoplamento. Esta interface é responsável pela amplificação do sinal a ser transmitido e pelo bloqueio do sinal de 60 $\mathrm{Hz}$.

A interface é constituída por dois circuitos: o amplificador de acoplamento e a rede de acoplamento. A rede de acoplamento realiza a tarefa de bloquear o sinal de $60 \mathrm{~Hz}$ de alta potência vindo da rede elétrica, ao mesmo tempo em que acopla o sinal a ser transmitido à rede.

A topologia de rede de acoplamento utilizada neste projeto é o modo diferencial indutivo, pois o mesmo provê um isolamento físico entre a rede elétrica e o sistema de transmissão, fornecendo assim uma maior segurança. A Figura 2 ilustra a rede de acoplamento e os dispositivos de proteção.

Este circuito é composto por um filtro LC paralelo de segunda ordem $\left(\mathrm{C}_{1}\right.$ e primário do transformador). $\mathrm{O}$ transformador foi projetado com a relação de espiras de 1:1. Os diodos servem para proteção contra sobretensão. $\mathrm{C}_{2}$ e $\mathrm{C}_{3}$ bloqueiam o sinal de $60 \mathrm{~Hz}$.

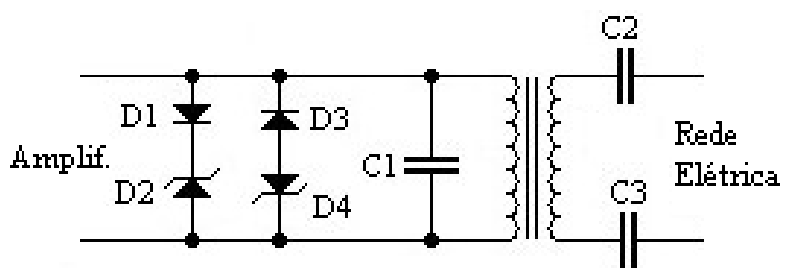

Figura 2 - Rede de acoplamento.

A Figura 3 ilustra o circuito amplificador utilizado para efetuar casamento entre a saída do gerador de tom e a entrada da rede de acoplamento e fornecer potência suficiente ao tom senoidal para transpor a rede de acoplamento. $\mathrm{O}$ amplificador projetado foi um de classe $\mathrm{AB}$ e seu ganho é de aproximadamente $12 \mathrm{~dB}$.

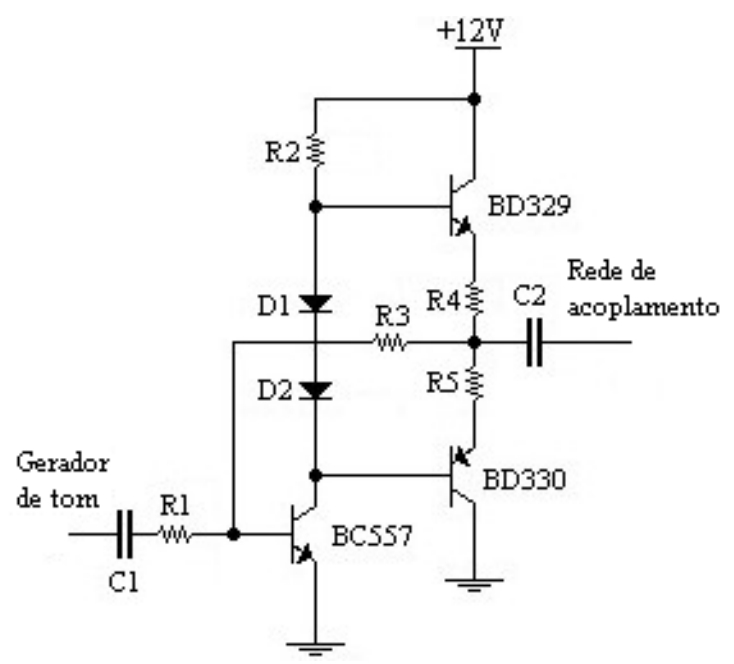

Figura 3 - Circuito amplificador. 


\section{GERADOR DE TOM}

O gerador de tom é implementado através do XR-2206. Este circuito integrado utiliza um PLL (Phase Locked Loop) projetado para aplicações de transmissões de dados. O XR-2206 é, basicamente, constituído de um pré-amplificador de entrada, um detector de fase e um oscilador controlado por tensão (VCO). O pré-amplificador é usado como um limitador, tal que os sinais de entrada acima de $10 \mathrm{mV}_{\text {rms }}$ são amplificados a um nível constante. O VCO é controlado por uma corrente de entrada ajustada por um resistor $\left(\mathrm{R}_{0}\right)$ e pela tensão de saída do conversor D/A. Este circuito está ilustrado na Figura 4.

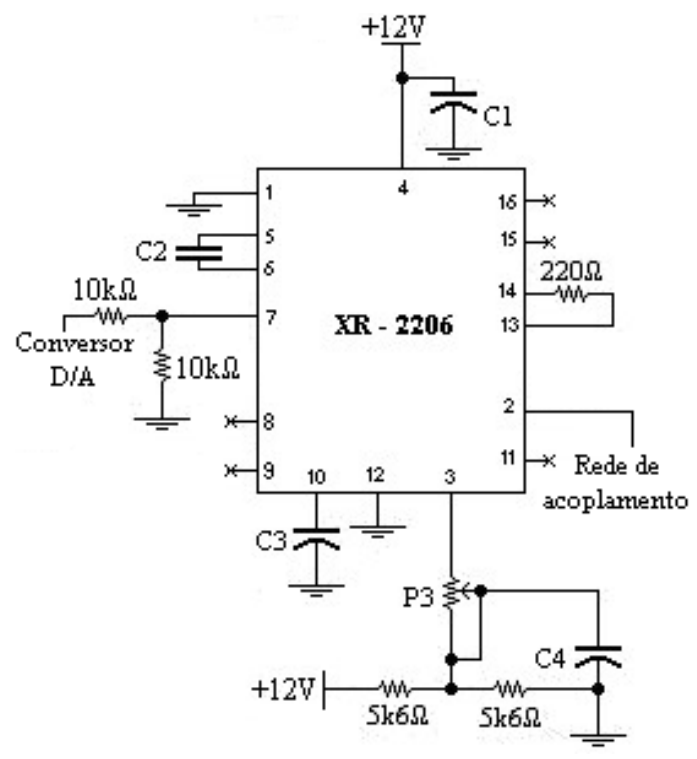

Figura 4 - Circuito gerador de tom.

A Figura 5 é uma foto da placa transmissora construída. Ela ficou um pouco menor que uma caneta Bic em comprimento. Foi usado um processo de fabricação artesanal. Mesmo assim, a placa ficou com um acabamento muito bom. Pode-se conseguir uma redução de dimensões usando uma placa dupla face.

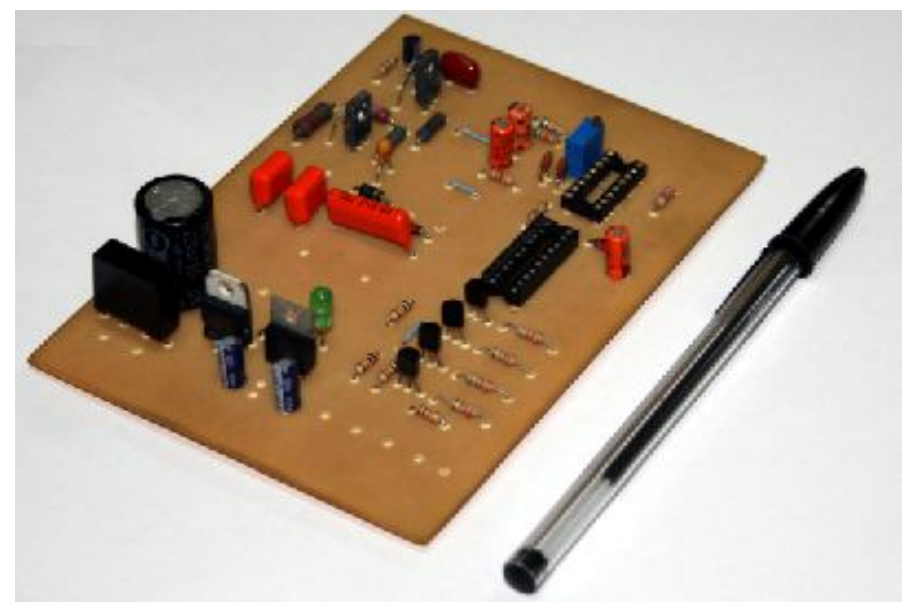

Figura 5 - Foto da placa transmissora. 


\section{SISTEMA RECEPTOR}

O sistema receptor é bem mais simples que o transmissor. O diagrama de blocos do receptor é ilustrado na Figura 6. Ambos os sistemas, receptor e transmissor, usam a rede elétrica para se comunicar. A rede de acoplamento utilizada no receptor é a mesma utilizada no transmissor.

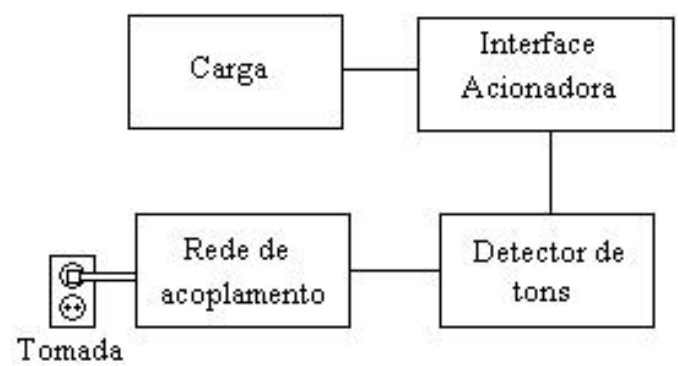

Figura 6 - Diagrama de blocos do sistema receptor.

\section{DETECTOR DE TOM}

O detector de tom é implementado através do circuito integrado XR-2211 que utiliza um PLL (Phase Locked Loop) projetado para aplicações de transmissões de dados. O XR-2211 é, basicamente, constituído de um pré-amplificador de entrada, um detector de fase e um oscilador controlado por tensão (VCO). O pré-amplificador é usado como um limitador tal que os sinais de entrada acima de $10 \mathrm{mVrms}$ são amplificados a um nível constante. $\mathrm{O}$ detector de fase age como uma porta digital XOR. O VCO é controlado por uma corrente de entrada ajustada pelo potenciômetro $\left(\mathrm{P}_{1}\right)$. O esquema do circuito detector de tom é ilustrado na Figura 7.

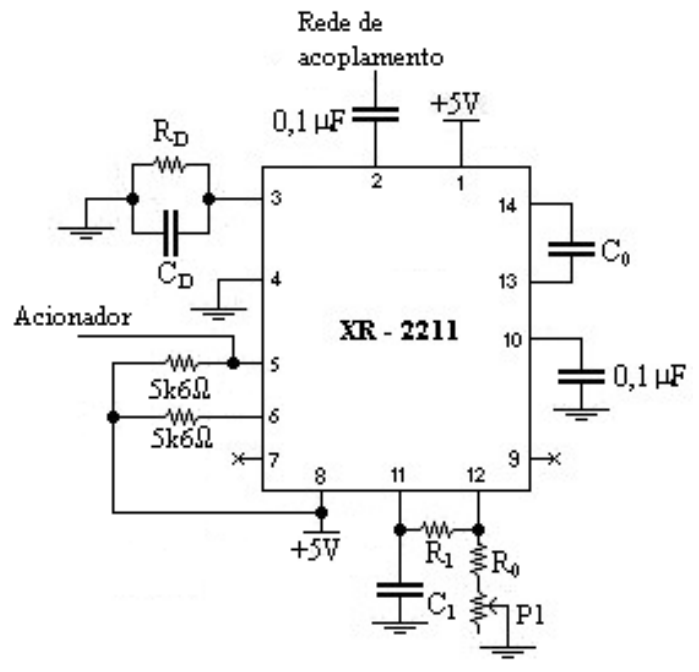

Figura 7 - Circuito detector de tom.

A foto da placa receptora construída é mostrada na Figura 8. Ela ficou bem menor que a placa transmissora devido à sua maior simplicidade. Foi usado o mesmo processo de 
fabricação artesanal. Apesar disto, placa ficou com um bom acabamento e com um tamanho bastante reduzido, como pode ser observado.

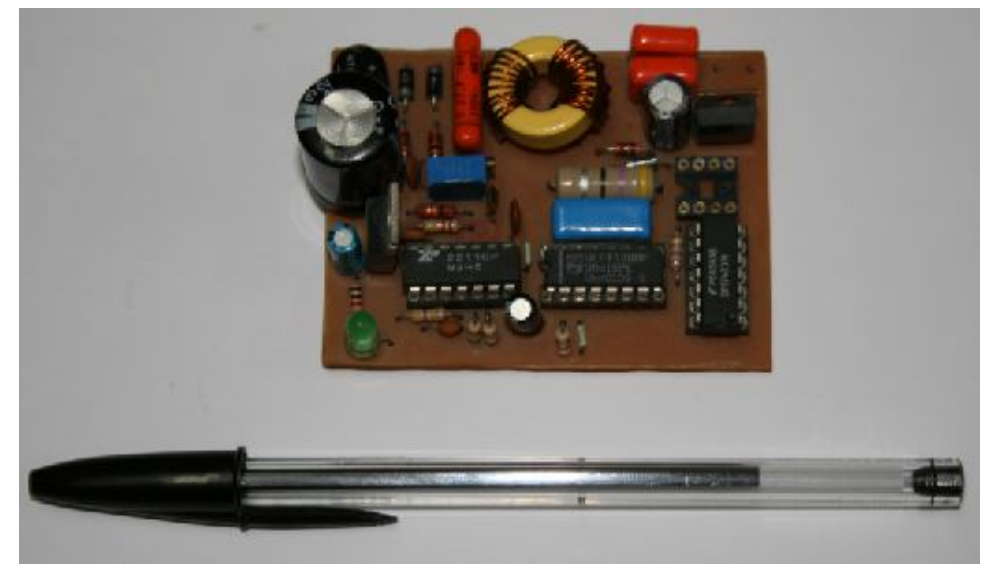

Figura 8 - Foto da placa receptora.

A Figura 9 ilustra as placas transmissora e receptora lado a lado, para que se possa ter idéia das dimensões das duas.

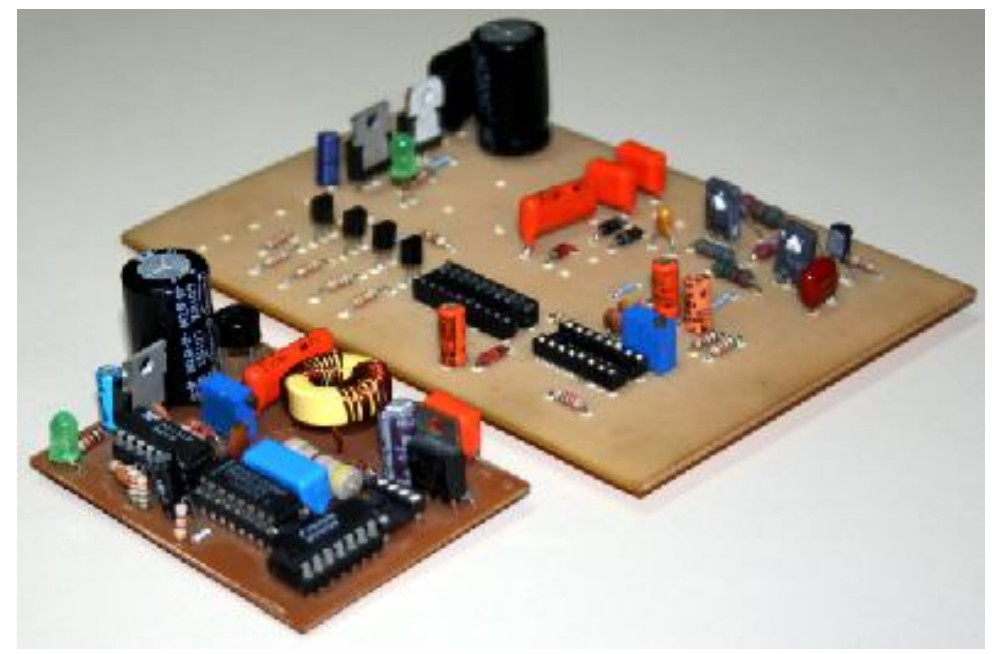

Figura 9 - Foto das placas transmissora e receptora.

\section{PROGRAMA COMPUTACIONAL}

O programa computacional foi desenvolvido em linguagem de programação JAVA, e é responsável pela interface homem-máquina. Nele, o usuário pode cadastrar os eventos. A Figura 10 ilustra a tela inicial do programa. Um dos campos indica os equipamentos disponíveis de serem acionados. Um botão para cadastrar eventos, um seletor para ativar o simulador e um campo que indica os eventos cadastrados para o dia corrente.

Clicando no botão eventos, a tela ilustrada na Figura 11 é aberta. Nela o usuário pode cadastrar o dia da semana do evento e a hora que ele quer que o equipamento seja 
acionado. Existem ainda dois botões que permitem ao usuário excluir um evento em particular ou todos os eventos cadastrados.

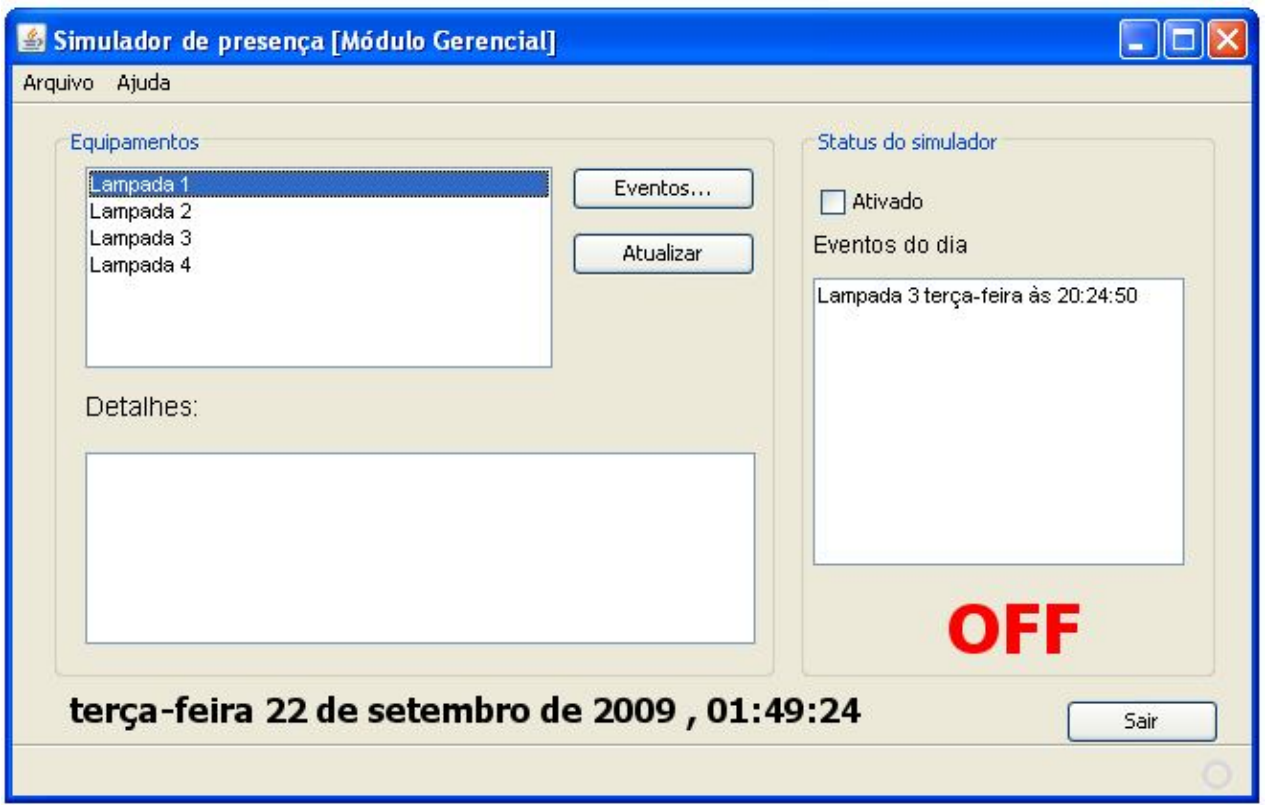

Figura 10 - Tela inicial do programa computacional.

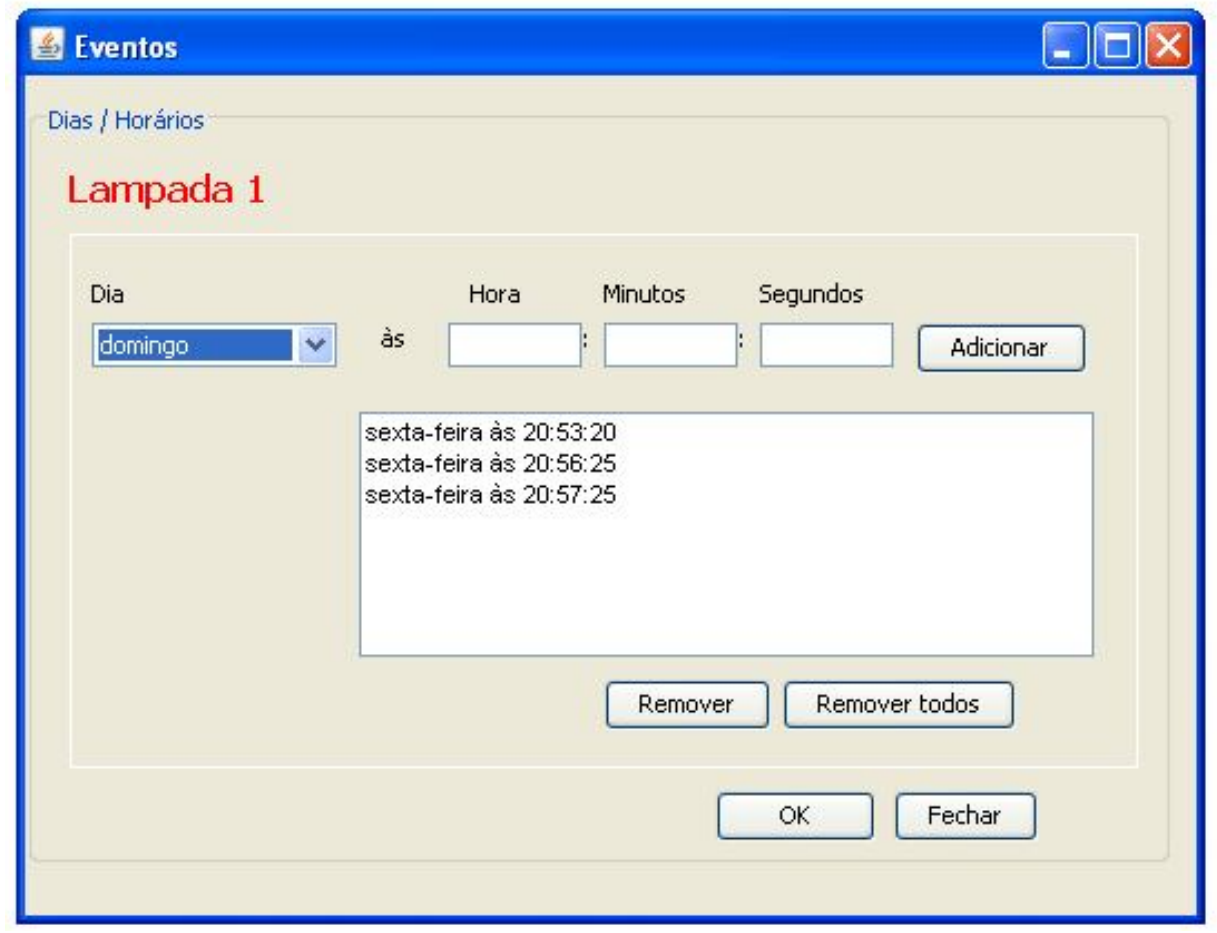

Figura 11 - Tela para cadastro de eventos. 


\section{CONCLUSÕES}

Nesse artigo foi apresentado um sistema de simulação de presença residencial, que utiliza uma interface eletrônica, para acionamento remoto de lâmpadas, utilizando a rede elétrica como canal de comunicação. Foram efetuados testes para mostrar a boa funcionalidade do equipamento. O sistema pode acionar não apenas lâmpadas, mas outros equipamentos elétricos como motores. A transmissão de dados através da rede elétrica é uma forma viável para comunicação de dados quando não se têm grandes distâncias. Sua aplicação em Automação Residencial mostra-se totalmente viável. O equipamento é conectado a um computador para que possa ser feita uma simulação de presença humana em residências, utilizando-se um programa computacional que controla o acionamento e desligamento de lâmpadas em horários selecionados pelo usuário.

\section{AGRADECIMENTOS}

Os autores agradecem à bolsa do Programa Institucional de Iniciação em Desenvolvimento Tecnológico e Inovação - PIBITI e aos técnicos de laboratório do Campus Zona Norte Aécio e Evantuy pelo grande auxílio na fabricação das placas.

\section{REFERÊNCIAS BIBLIOGRÁFICAS}

1. ABRAHAM, K. C. e ROY, S., A Novel High-Speed PLC Communication Modem. IEEE Transactions on Power Delivery, Vol. 7, (4), 1992.

2. AHMED, A., Eletrônica de Potência, Prentice Hall do Brasil, 2000.

3. CAMPOS, A. L. P. S., MOREIRA, R. C. O. e ARAÚJO, L. M., Análise de Desempenho de uma Rede de Computadores que Utiliza o Padrão Homeplug 1.0. Revista IEEE América Latina, Vol. 5, p. 360-366, 2007.

4. CAMPOS, A. L. P. S.; MENDONÇA JÚNIOR, J., Sistema Microcontrolado para Acionamento Remoto de Equipamentos Através da Rede Elétrica. In: II Connepi 2007, 2007, João Pessoa. Anais do II Connepi, 2007.

5. CAMPOS, A. L. P. S.; MOTENEGRO, R. H. M., Análise Qualitativa da Transmissão de Dados Através da Rede Elétrica. In: I Congresso de Pesquisa e Inovação da Rede Norte Nordeste de Educação Tecnológica, 2006, Natal. Anais do I Connepi, 2006.

6. KELly, G, Home Automation: Past, Present \& Future, Electronics Australia, Fevereiro, 1997.

7. MAINARDI, E., BANZI, S., BONFIÈ, M. e BEGHELLI, S., A low-cost Home Automation System based on Power-Line Communication Links, 22nd International Symposium on Automation and Robotics in Construction, ISARC 2005 - September 11-14, 2005, Ferrara, Itália.

8. MARIOTONI, C. A. e ANDRADE Jr., E. P., Descrição de Sistemas de Automação Predial Baseados em Protocolos PLC Utilizados em Edifícios de Pequeno Porte e Residências, Revista de Automação e Tecnologia de Informação. Volume 1, número 1, 2002.

9. NASHELSKY, L. e BOYLESTAD, R. L. ATTIA, Y. A. I. e KITCHENER, J. A. Dispositivos Eletrônicos e Teoria de Circuitos. Prentice Hall do Brasil, 2004. 
10. TOCCI, R. J., WIDMER, N. S. e MOSS, G. Y L., Sistemas Digitais - Princípios e Aplicações, Prentice Hall do Brasil, 2007. 